Supporting Information

\title{
Lanthanide Binding Tags as Luminescent Probes for Studying Protein Interactions
}

Bianca R. Sculimbrene and Barbara Imperiali*

\author{
Department of Chemistry, Massachusetts Institute of Technology \\ 77 Massachusetts Ave. Cambridge, MA 02139 USA \\ email: imper@mit.edu
}

\section{Complete citation for reference 25:}

Songyang, Z.; Shoelson, S.E.; Chaudhuri, M.; Gish, G.; Pawson, T.; Haser, W.G.; King, F.;

Roberts, T.; Ratnofsky, S.; Lechleider, R. J.; Neel, B.G.; Birge, R.B.; Fajardo, J.E.; Chou, M.M.; Hanafusa, H.; Schaffausen, B.; Cantley, L.C. Cell, 1993, 72, 767-778.

\section{Peptide Synthesis.}

Peptides were prepared by automated solid phase peptide synthesis (SPPS) on either an Advanced ChemTech 396 synthesizer or Applied Biosystems Inc. 431A employing standard 9fluoenylmethoxycarbonyl (FMOC) protected amino acids, 1-hydroxy-1H-benzotriazole (HOBt), and $O$-benzotriazol-1yl)- $N, N, N^{\prime}, N^{\prime}$-tetramethyluronium hexafluorophosphate (HBTU) coupling reagents (from Novabiochem) and piperidine deprotections. Final deprotections and cleavage from the polyaniline-poly(ethylene)glycol-polystyrene resin (PAL-PEG-PS, Perseptive Biosystems) was carried out with $90 \%$ trifluoroacetic acid, 5\% methylene chloride, $2.5 \%$ triisopropyl silane, $2.5 \% \mathrm{H}_{2} \mathrm{O}$ for 3 hours to afford the peptides with C-terminal amides and $\mathrm{N}$ terminal amines. Peptides were purified by reverse phase HPLC with a Waters 600 automated control module on a $\mathrm{YMC}_{18}$ preparative column eluting with acetonitrile/water containing $0.1 \%$ TFA. For detection, a Waters 2487 dual wavelength absorbance detector was used to record at $228 \mathrm{~nm}$ and $280 \mathrm{~nm}$. Standard HPLC conditions were 5\% acetonitrile for 5 minutes followed by a linear gradient from $5 \%$ to $95 \%$ acetonitrile for 30 minutes. Purity was confirmed by analytical HPLC and correct mass validated by ESI-MS on a Mariner electrospray mass spectrometer (PerSpective Biosystems). Phosphopeptides were synthesized analogous to the above procedure employing commercially available FMOC-Tyr( $\mathrm{PO}(\mathrm{OBn}) \mathrm{OH})$.

\section{Bodipy Labeling of Peptides.}

Bodipy labeling was performed on HPLC purified peptides with N-terminal amines. The lyophilized, pure peptide was dissolved in $0.1 \mathrm{M} \mathrm{NaHCO}_{3}$ and the concentration was determined on a Shimazu Spectrophotometer by recording the absorbance at $280 \mathrm{~nm}$ in $6 \mathrm{M}$ Guanidine, using the Extinction Coefficient of tyrosine $\left(\varepsilon_{\mathrm{C}}=1280 \mathrm{M}^{-1} \mathrm{~cm}^{-1}\right)$ and phosphotyrosine $\left(\varepsilon_{\mathrm{C}}=652\right.$ $\left.\mathrm{M}^{-1} \mathrm{~cm}^{-1}\right) .0 .52 \mu$ moles of peptide was added to $1.3 \mu$ moles of 4,4-difluoro-5,7-dimethyl-4-bora3a,4a-diaza-s-indacene-3-propionic acid, succinimidyl ester (BODIPY ${ }^{\circledR}$ FL, SE, from Molecular Probes) or 6-(4,4-difluoro-1,3-dimethyl-5-(4-methoxyphenyl)-4-bora-3a-4a-diazo- $s$-indacene-2propionyl)amino)-hexanoic acid, succinimidyl ester (BODIPY ${ }^{\circledR}$ TMR-X, SE, from Molecular Probes) dissolved in $50 \mu \mathrm{L}$ of DMSO. The reactions were shaken for 4 hours and then purified by preparative HPLC with a Waters 600 automated control module on a YMC $\mathrm{C}_{18}$ preparative column eluting with acetonitrile/water containing $0.1 \%$ TFA. For detection, a Waters 2487 dual wavelength absorbance detector was used to record at $228 \mathrm{~nm}$ and $350 \mathrm{~nm}$. Standard HPLC conditions were a linear gradient from $7 \%$ to $100 \%$ acetonitrile for 30 minutes. Purity was confirmed by analytical HPLC and correct mass validated by ES-MS on a Mariner electrospray 
mass spectrometer (PerSpective Biosystems). Peptide concentration was determined by measuring the UV in $\mathrm{MeOH}$ at $504 \mathrm{~nm}$ for BODIPYFL $\left(\varepsilon_{\mathrm{C}}=82,000 \mathrm{M}^{-1} \mathrm{~cm}^{-1}\right)$ and $540 \mathrm{~nm}\left(\varepsilon_{\mathrm{C}}=\right.$ $\left.60,000 \mathrm{M}^{-1} \mathrm{~cm}^{-1}\right)$

\section{Peptide Characterization.}

Crk-PP: ahx-QpYDHPNI
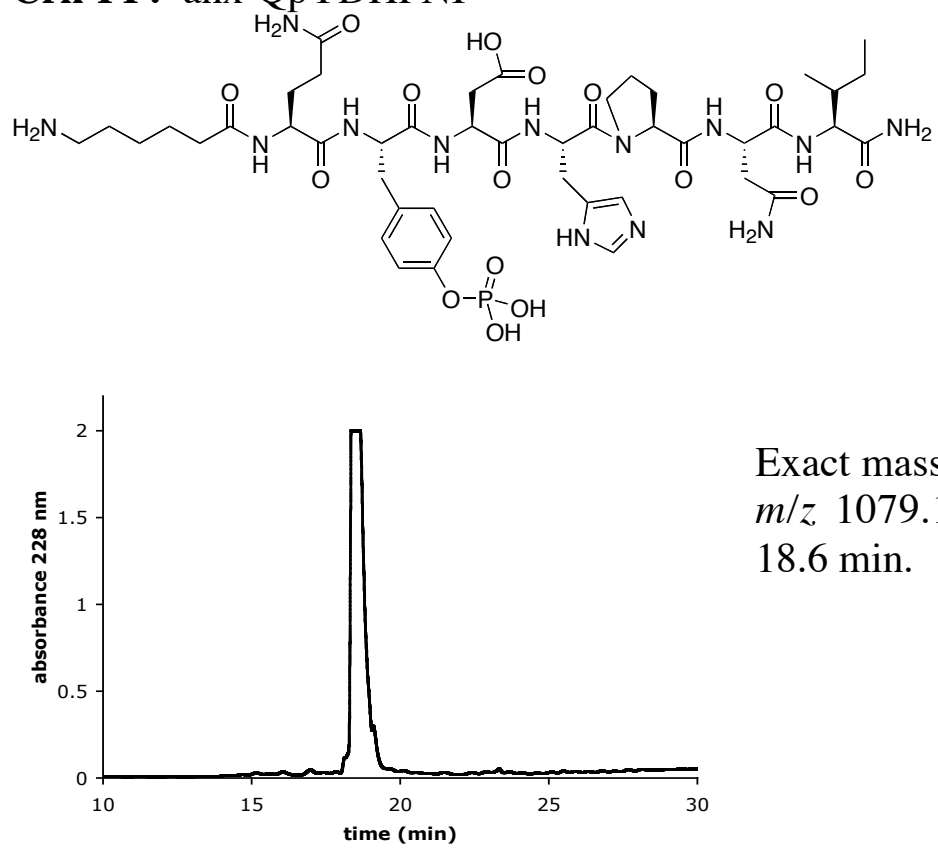

Exact mass calcd for $\left[\mathrm{C}_{45} \mathrm{H}_{68} \mathrm{~N}_{13} \mathrm{O}_{16} \mathrm{P}+\mathrm{H}\right]+$ requires $m / z$ 1079.1. Found 1078.4. HPLC retention time: $18.6 \mathrm{~min}$.

Src-PP: ahx-EPQpYEEIPIYL

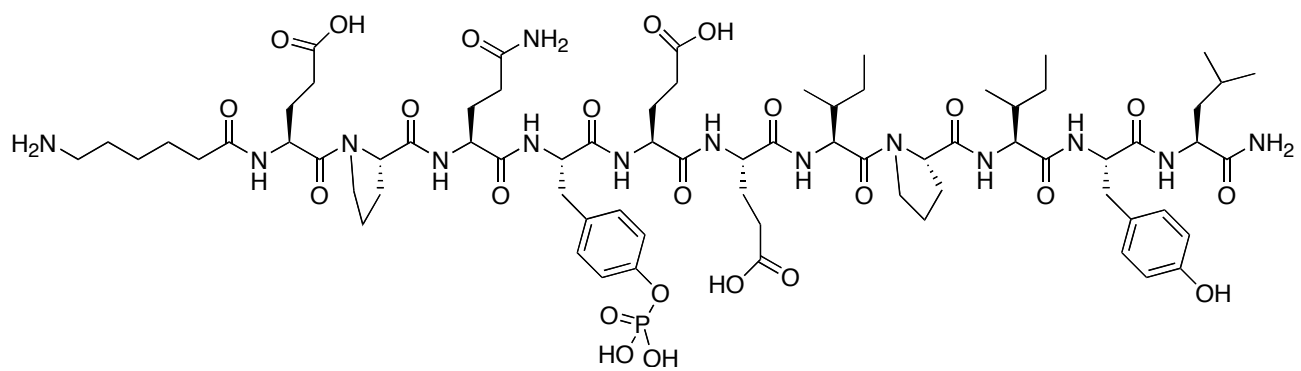

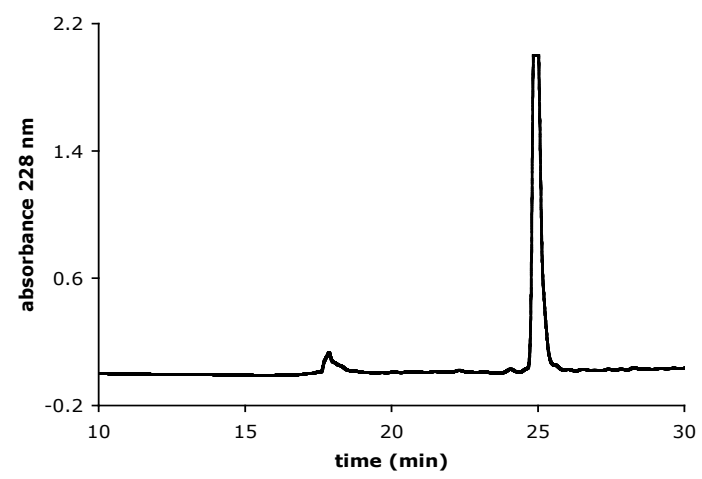

Exact mass calcd for $\left[\mathrm{C}_{72} \mathrm{H}_{109} \mathrm{~N}_{14} \mathrm{O}_{24} \mathrm{P}+\mathrm{H}\right]$ '+ requires $\mathrm{m} / \mathrm{z}$ 1586.7. Found 1586.7. HPLC retention time: $25.0 \mathrm{~min}$. 
BODIPY_FL-Src-PP: BODIPY_FL-ahx-EPQpYEEIPIYL

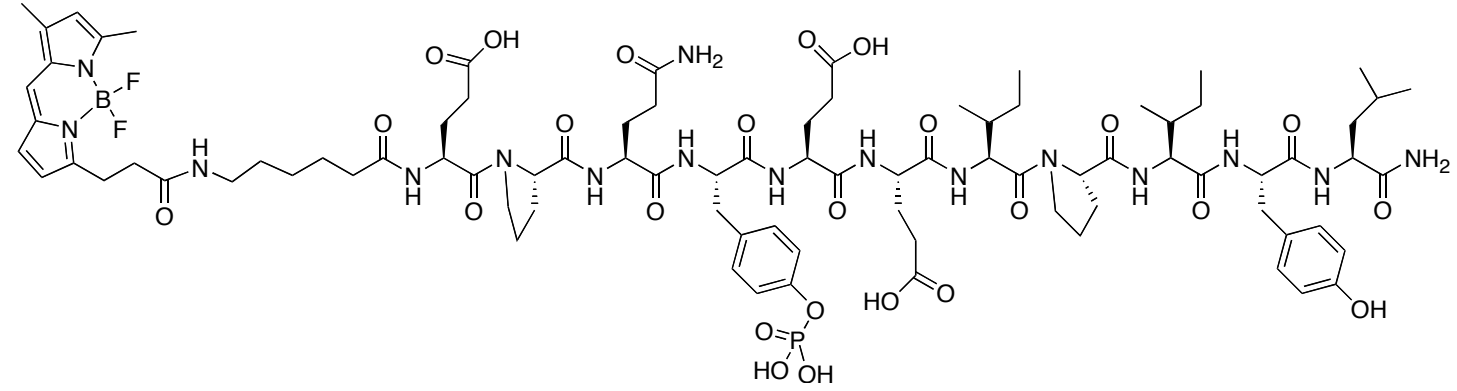

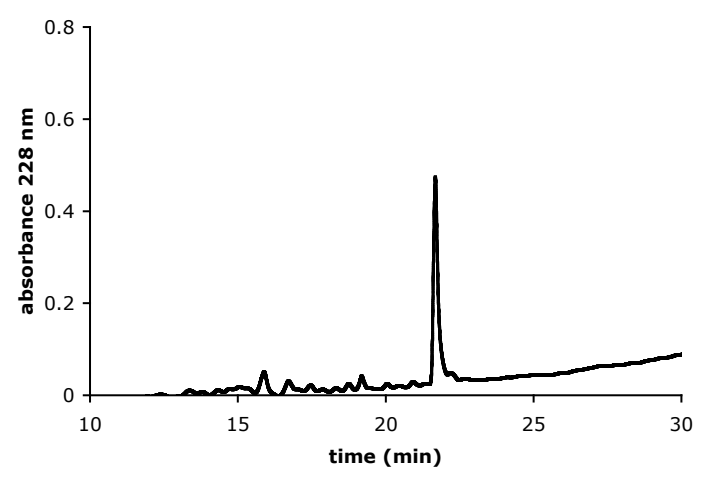

Exact mass calcd for $\left[\mathrm{C}_{86} \mathrm{H}_{122} \mathrm{BF}_{2} \mathrm{~N}_{16} \mathrm{O}_{25} \mathrm{P}+\mathrm{H}\right]+$ requires $\mathrm{m} / \mathrm{z}$ 1860.8. Found 1860.9.

HPLC retention time: $21.7 \mathrm{~min}$.

BODIPY_FL-Src-CP: BODIPY_FL-ahx-EPQYEEIPIYL
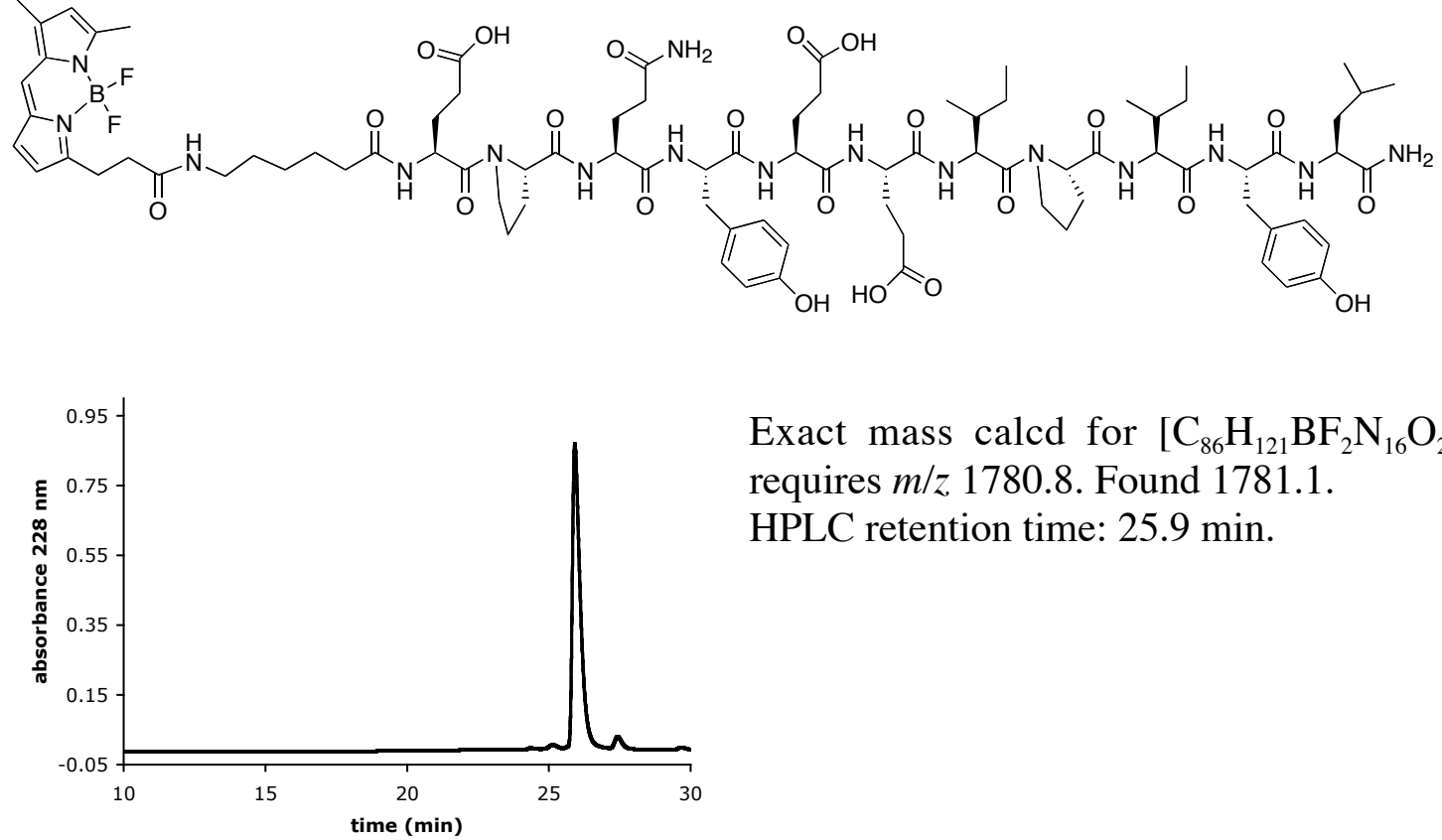

Exact mass calcd for $\left[\mathrm{C}_{86} \mathrm{H}_{121} \mathrm{BF}_{2} \mathrm{~N}_{16} \mathrm{O}_{22}+\mathrm{H}\right]+$ requires $m / z$ 1780.8. Found 1781.1.

HPLC retention time: 25.9 min. 
BODIPY_FL-Crk-PP: BODIPY_FL-ahx-QpYDHPNI
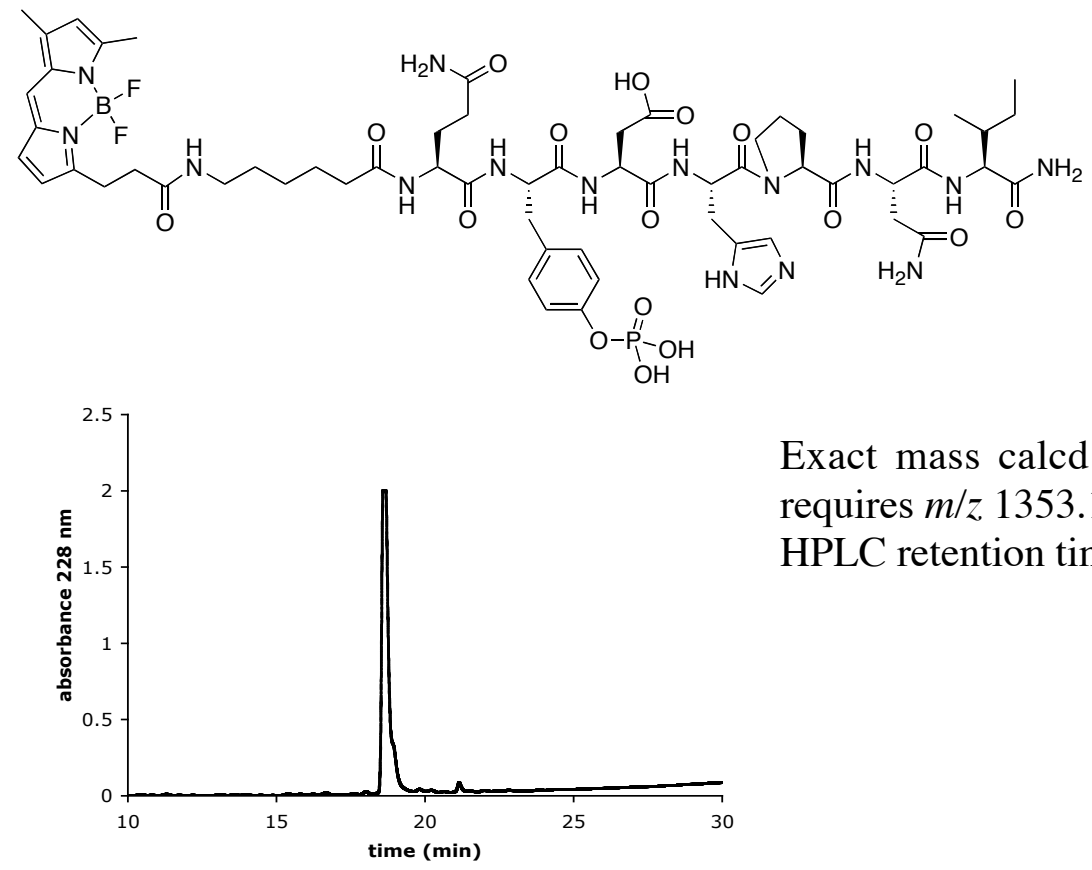

Exact mass calcd for $\left[\mathrm{C}_{59} \mathrm{H}_{81} \mathrm{BF}_{2} \mathrm{~N}_{15} \mathrm{O}_{17} \mathrm{P}+\mathrm{H}\right]+$ requires $m / z$ 1353.1. Found 1353.8.

HPLC retention time: $18.7 \mathrm{~min}$.

BODIPY_FL-Crk-PP: BODIPY_FL-ahx-QYDHPNI
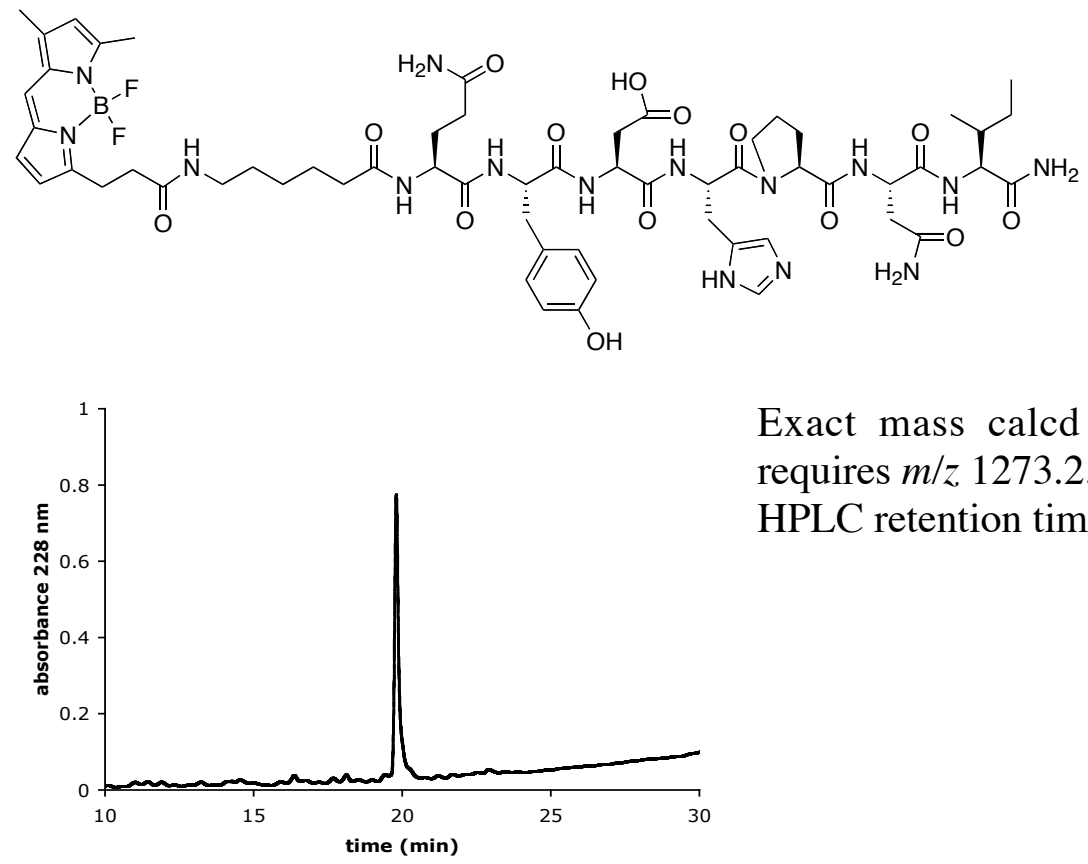

Exact mass calcd for $\left[\mathrm{C}_{59} \mathrm{H}_{80} \mathrm{BF}_{2} \mathrm{~N}_{15} \mathrm{O}_{14}+\mathrm{H}\right]+$ requires $m / z$ 1273.2. Found 1273.8.

HPLC retention time: $19.8 \mathrm{~min}$. 
BODIPY_TMR-Src-PP: BODIPY_TMR-ahx-EPQpYEEIPIYL

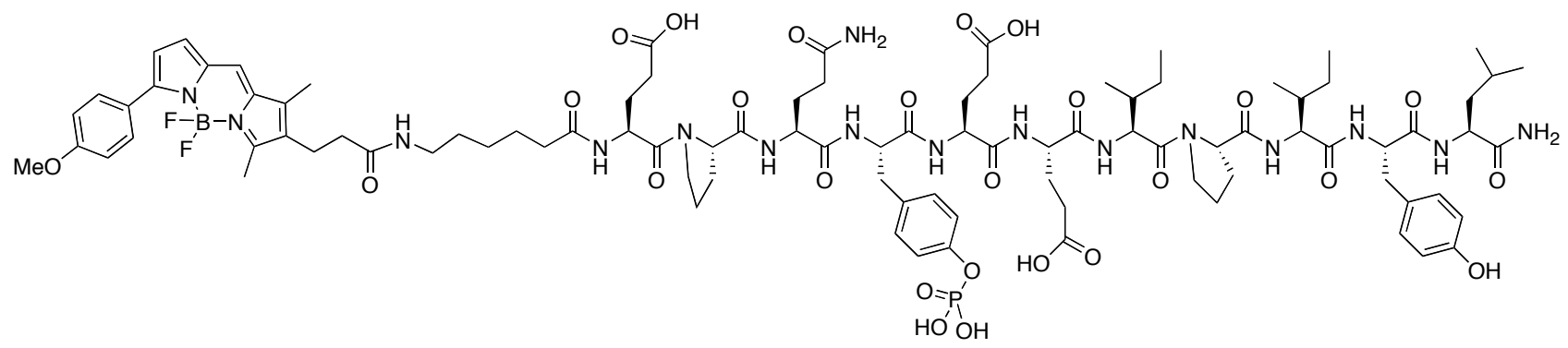

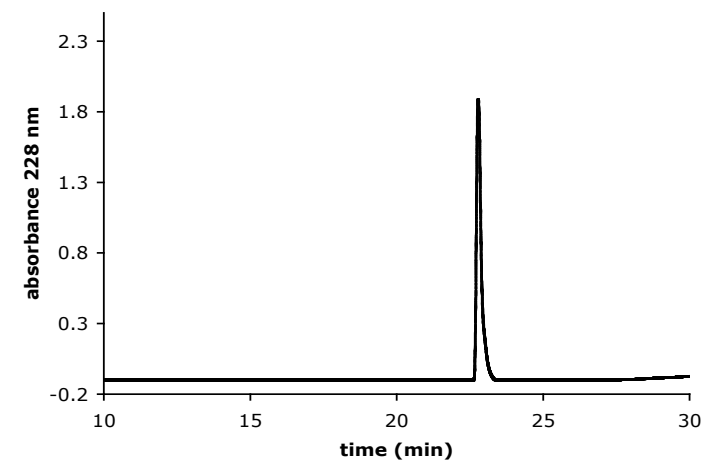

Exact mass calcd for $\left[\mathrm{C}_{93} \mathrm{H}_{128} \mathrm{BF}_{2} \mathrm{~N}_{16} \mathrm{O}_{26} \mathrm{P}+\mathrm{H}\right]+$ requires $\mathrm{m} / \mathrm{z}$ 1966.8. Found 1966.8. HPLC retention time: $22.8 \mathrm{~min}$.

BODIPY_TMR-Src-CP: BODIPY_TMR-ahx-EPQYEEIPIYL

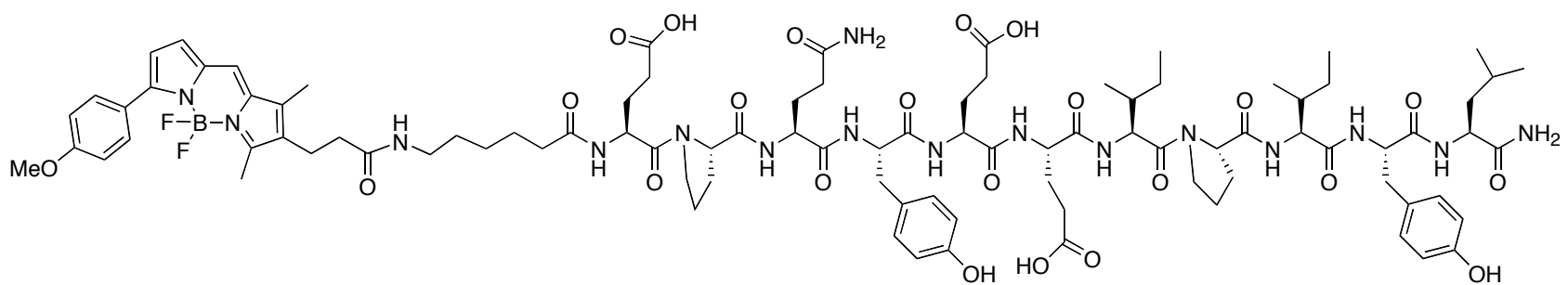

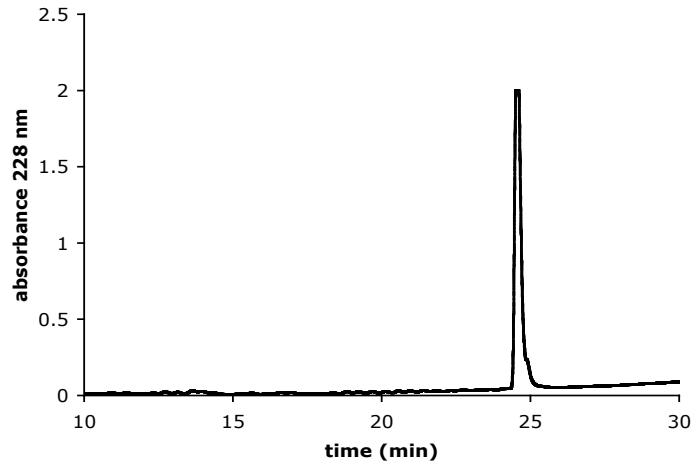

Exact mass calcd for $\left[\mathrm{C}_{93} \mathrm{H}_{127} \mathrm{BF}_{2} \mathrm{~N}_{16} \mathrm{O}_{23}+\mathrm{Na}\right]+$ requires $m / z$ 1908.9. Found 1908.2. HPLC retention time: $24.6 \mathrm{~min}$. 
SH2 Domains: Clones expressing SH2 domain-GST conjugates were received from Prof. Martin Schwartz (University of Virginia).

Plasmid Preparation of pGEX_Src-LBT. A DNA sequence encoding Src-SH2 domain and LBT was inserted into the pGEX4T-2 plasmid (Amersham Biosciences) by standard PCR with a megaprimer strategy. For primers longer than $100 \mathrm{bp}$ two smaller primers were elongated with PCR to generate a double-stranded megaprimer.

$50 \mu \mathrm{L} 10 \mathrm{X}$ HIFI buffer

$32.5 \mu \mathrm{L} 10 \mathrm{mM}$ dNTPs

$19.5 \mu \mathrm{L} 50 \mathrm{mM} \mathrm{MgCl}{ }_{2}$

$6.5 \mathrm{~mL}$ forward primer $(0.5 \mu \mathrm{g} / \mu \mathrm{L})$

$6.5 \mu \mathrm{L}$ reverse primer $(0.5 \mu \mathrm{g} / \mu \mathrm{L})$

$380 \mu \mathrm{L}$ sterile $\mathrm{H}_{2} \mathrm{O}$

$5 \mathrm{uL}$ Taq HIFI polymerase (added last)

Forward Primer

TCGTGATACGCCTATTTTTATAGGTAAGCTTGGTGGCTTTATTGATACCAACAACGAT GGCTGGA

Reverse Primer:

CCGCTCGAGTTAGCCTTCTTCCAGCAGCAGTTCATCGCCTTCAATCCAGCATCGTTGT TGGTAT

Thermal Cycler for PCR: red $=$ temperature $\left({ }^{\circ} \mathrm{C}\right)$ blue $=$ time $(\mathrm{sec})$

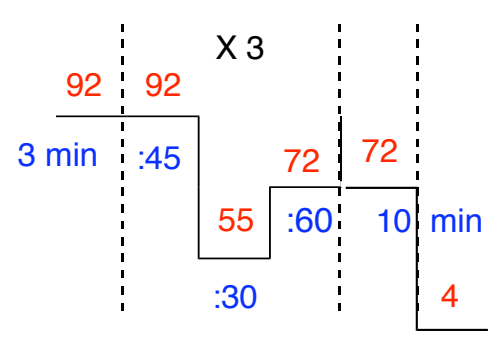

The PCR reaction mixture was purified on a $4 \%$ agarose gel and stained with ethidium bromide. The DNA was cut out of the agarose and extracted using the QIAquick gel extraction kit to generate the megaprimer.

$5 \mu \mathrm{L} 10 \mathrm{X}$ Pfu buffer

$0.4 \mu \mathrm{L} 10 \mathrm{mM}$ dNTPs

$1 \mu \mathrm{L}$ megaprimer primer

$1 \mu \mathrm{L}$ forward primer $(0.5 \mu \mathrm{g} / \mu \mathrm{L})$

$1 \mu \mathrm{L}$ mini prep vector DNA [pGEX-(Src-SH2)]

40.6 $\mu \mathrm{L}$ sterile $\mathrm{H}_{2} \mathrm{O}$

$1 \mu \mathrm{L}$ Pfu turbo (added last) 
Megaprimer:

TCGTGATACGCCTATTTTTATAGGTAAGCTTGGTGGCTTTATTGATACCAACAACGAT GGCTGGATTGAAGGCGATGAACTGCGCTGGAAGAAGGCTAACTCGAGCGG

Forward Primer:

CGGGATCCTGGTACTTTGGGAAGATCACTCGGTC

Thermal Cycler for PCR: red $=$ temperature $\left({ }^{\circ} \mathrm{C}\right)$ blue $=$ time $(\mathrm{sec})$

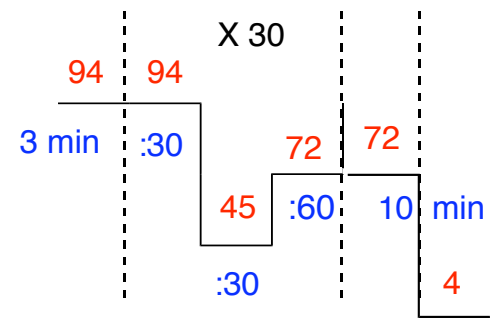

The PCR reaction mixture was purified on a $1.5 \%$ agarose gel and stained with ethidium bromide The DNA was cut out of the agarose and extracted using the QIAquick gel extraction kit.

pGex4T-2 vector digestion

$40 \mu \mathrm{L}$ miniprep pGEX4T-2 vector $(1 \mu \mathrm{g})$

$5 \mu \mathrm{L}$ BamH1 10X buffer

$0.5 \mu \mathrm{L}$ 100X BSA

$2.5 \mu \mathrm{L} \mathrm{BamH1}$

$2.5 \mu \mathrm{L}$ Xho $\underline{\text { Src-LBT Insert digestion }}$

$40 \mu \mathrm{L}$ PCR rxn

$5 \mu \mathrm{L}$ BamH1 10X buffer

$0.5 \mu \mathrm{L} 100 \mathrm{X}$ BSA

$2.5 \mu \mathrm{L}$ BamH1

$2.5 \mu \mathrm{L}$ Xho

The digestion reactions were incubated in $500 \mu \mathrm{L}$ eppendorf tubes at $25^{\circ} \mathrm{C}$ overnight. The next morning the pGEX4T-2 vector digestion was incubated with $1.5 \mu \mathrm{L}$ of CIP at $37{ }^{\circ} \mathrm{C}$ for $1 \mathrm{hr}$. The DNA was purified on a $0.8 \%$ agarose gel, and stained with ethidium bromide. The digested DNA was cut from the gel and extracted with a QIAquick gel extraction kit.

$\underline{\text { Vector ligation }}$

$5 \mu \mathrm{L}$ pGEX4T-2 cut/cip treated (25 ng)

$3 \mu \mathrm{L}$ Src-LBT insert cut (10 ng)

$1 \mu \mathrm{L} 10 \mathrm{X}$ ligation buffer (vortexed)

$1 \mu \mathrm{L}$ T4 ligase
Control ligation

$5 \mu \mathrm{L}$ pGEX4T-2 (25 ng)

$3 \mu \mathrm{L} \mathrm{H}_{2} \mathrm{O}$

$1 \mu \mathrm{L} 10 \mathrm{X}$ ligation buffer (vortexed)

$1 \mu \mathrm{L}$ T4 ligase

The ligation mixtures were transformed into DH5 $\alpha$ cells and grown on carbencillin resistant plates. Selected colonies were sequenced at the Biopolymers Laboratory at MIT.

DNA Sequence of pGEX4T-2_(Src-LBT)

GGATCCTGGTACTTTGGGAAGATCACTCGTCGGGAGTCCGAGCGGCTGCTGCTCAAC CCCGAAAACCCCCGGGGAACCTTCTTGGTCCGGGAGAGCGAGACGACAAAAGGTGC CTATTGCCTCTCCGTTTCTGACTTTGACAACGCCAAGGGGCTCAATGTGAAGCACTA CAAGATCCGCAAGCTGGACAGCGGCGGCTTCTACATCACCTCACGCACACAGTTCA GCAGCCTGCAGCAGCTGGTGGCCTACTACTCCAAACATGCTGATGGCTTGTGCCACC 
GCCTGACCAACGTCTGCCCCACGTCCAAGCCCCAGACCCAGGGACTCGCCAAGGAC GCGTGGGAATTCTTGAAGACGAAAGGGCCTCGTGATACGCCTATTTTTATAGGTAAG CTTGGTGGCTTTATTGATACCAACAACGATGGCTGGATTGAAGGCGATGAACTGCTG CTGGAAGAAGGCTAA

\section{Protein sequence of GST-Src-LBT}

MSPILGYWKIKGLVQPTRLLLEYLEEKYEEHLYERDEGDKWRNKKFELGLEFPNLPYYI DGDVKLTQSMAIIRYIADKHNMLGGCPKERAEISMLEGAVLDIRYGVSRIAYSKDFETLK VDFLSKLPEMLKMFEDRLCHKTYLNGDHVTHPDFMLYDALDVVLYMDPMCLDAFPKL VCFKKRIEAIPQIDKYLKSSKYIAWPLQGWQATFGGGDHPPKSDLVPRGSWYFGKITRR ESERLLLNPENPRGTFLVRESETTKGAYCLSVSDFDNAKGLNVKHYKIRKLDSGGFYITS RTQFSSLQQLVAYYSKHADGLCHRLTNVCPTSKPQTQGLAKDAWEFLKTKGPRDTPIFI GKLGGFIDTNNDGWIEGDELLLEEG

Plasmid Preparation of pGEX_Crk-LBT. A DNA sequence encoding the Crk-SH2 domain was inserted into the BamH1 and HindIII cut sites of pGEX4T-2(Src-LBT) plasmid (discussed above) by standard PCR cloning techniques.

$50 \mu \mathrm{L}$ 10X HIFI buffer

$32.5 \mu \mathrm{L} 10 \mathrm{mM}$ dNTPs

$19.5 \mu \mathrm{L} 50 \mathrm{mM} \mathrm{MgSO}_{4}$

$6.5 \mu \mathrm{L}$ forward primer

$6.5 \mu \mathrm{L}$ reverse primer

$7 \mu \mathrm{L}$ miniprep pGEX4T-2(Crk)

$373 \mu \mathrm{L}$ sterile $\mathrm{H}_{2} \mathrm{O}$

$5 \mu \mathrm{L}$ HIFI Taq polymerase

forward primer:

CGGGATCCGGGTCCGAGGACCGGGGGAGCTGGT

reverse primer

CCCAAGCTTTCGGGAAACTGGTTCTATCAAGGTT

Thermal Cycler for PCR: red $=$ temperature $\left({ }^{\circ} \mathrm{C}\right)$ blue $=$ time $(\mathrm{sec})$

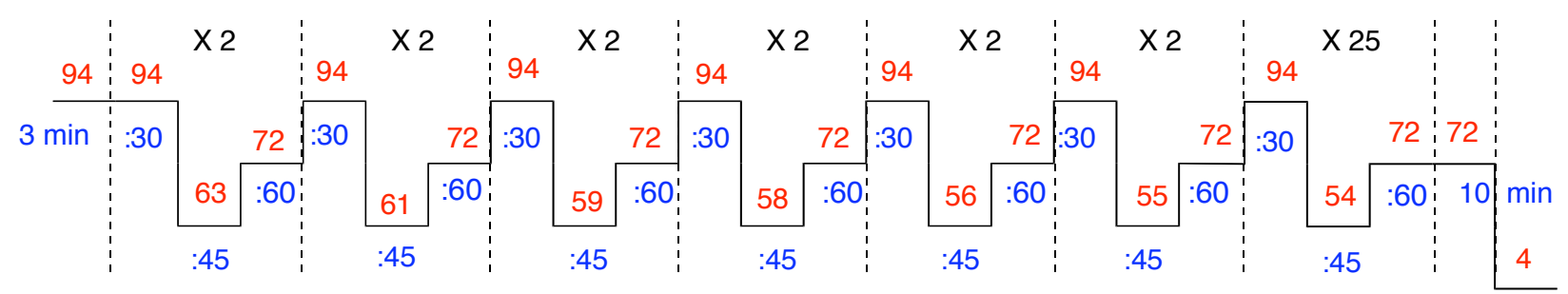

The PCR reaction mixture was purified on a $1.5 \%$ agarose gel and stained with ethidium bromide The DNA was cut out of the agarose and extracted using the QIAquick gel extraction kit. 
pGex4T-2(Src-LBT) vector digestion $11 \mu \mathrm{L}$ pGex4T-2(Src-LBT) $(5 \mu \mathrm{g})$

$5 \mu \mathrm{L}$ 10X NEB buffer \#2

$0.5 \mu \mathrm{L} 100 \mathrm{X}$ BSA

$2.5 \mu \mathrm{L}$ BamH1

$2.5 \mu \mathrm{L}$ HindIII

$29 \mu \mathrm{L}$ sterile $\mathrm{H}_{2} \mathrm{O}$
Crk Insert digestion

$40 \mu \mathrm{L}$ PCR rxn

$5 \mu \mathrm{L} 10 \mathrm{X}$ NEB buffer \#2

$0.5 \mu \mathrm{L} 100 \mathrm{X}$ BSA

$2.5 \mu \mathrm{L}$ BamH1

$2.5 \mu \mathrm{L}$ HindIII

The digestion reactions were incubated in $500 \mu \mathrm{L}$ eppendorf tubes at $25^{\circ} \mathrm{C}$ overnight. The next morning the vector digestion was incubated with $1.5 \mu \mathrm{L}$ of CIP at $37{ }^{\circ} \mathrm{C}$ for $1 \mathrm{hr}$. The DNA was purified on a $0.8 \%$ agarose gel, and stained with ethidium bromide. The digested DNA was cut from the gel and extracted with a QIAquick gel extraction kit.

Vector ligation

$5 \mu \mathrm{L}$ pGEX4T-2(LBT) cut/cip treated (25 ng)

$3 \mu \mathrm{L} \mathrm{Crk}$ insert cut (10 ng)

$1 \mu \mathrm{L} 10 \mathrm{X}$ ligation buffer (vortexed)

$1 \mu \mathrm{L}$ T4 ligase
Control ligation

$5 \mu \mathrm{L}$ pGEX4T-2(LBT) (25 ng)

$3 \mu \mathrm{L} \mathrm{H}_{2} \mathrm{O}$

$1 \mu \mathrm{L} 10 \mathrm{X}$ ligation buffer (vortexed)

$1 \mu \mathrm{L}$ T4 ligase

The ligation mixtures were transformed into DH5 $\alpha$ cells and grown on carbencillin resistant plates. Selected colonies were sequenced at the Biopolymers Laboratory at MIT.

DNA Sequence of pGEX4T-2_(Crk-LBT)

GGATCCGGGTCCGAGGACCGGGGGAGCTGGTACTGGGGGCGGCTGAGCCGGGGCG ACGCGGTGTCGCTGCTGCAGGGGCAACGCCACGGGACCTTCCTGGTGCGCGACTCG GGCTCCATCCCCGGCGACTTCGTGCTCTCGGTGTCCGAGAGCTCCCGCGTCTCGCAC TACATCGTCAACAGCCTGGGGCCGGCGGGAGGCCGGAGGGCCGGCGGCGAGGGCC CTGGGGCCCCGGGGTTGAATCCCACCAGATTTCGAATAGGTGACCAGGAGTTTGATT CTTTGCCATCTTTACTGGAATTCTACAAAATACACTATTTGGACACTACAACCTTGAT AGAACCAGTTTCCCGAAAGCTTGGTGGCTTTATTGATACCAACAACGATGGCTGGAT TGAAGGCGATGAACTGCTGCTGGAAGAAGGCTAA

\section{Protein sequence of GST-Crk-LBT \\ MSPILGYWKIKGLVQPTRLLLEYLEEKYEEHLYERDEGDKWRNKKFELGLEFPNLPYYI DGDVKLTQSMAIIRYIADKHNMLGGCPKERAEISMLEGAVLDIRYGVSRIAYSKDFETLK VDFLSKLPEMLKMFEDRLCHKTYLNGDHVTHPDFMLYDALDVVLYMDPMCLDAFPKL VCFKKRIEAIPQIDKYLKSSKYIAWPLQGWQATFGGGDHPPKSDLVPRGSGSEDRGSWY WGRLSRGDAVSLLQGQRHGTFLVRDSGSIPGDFVLSVSESSRVSHYIVNSLGPAGGRRA GGEGPGAPGLNPTRFRIGDQEFDSLPSLLEFYKIHYLDTTTLIEPVSRKLGGFIDTNNDGW IEGDELLLEEG}

\section{Protein Expression and purification}

The LBT-containing plasmids were transformed into BL21-Gold(DE3) competent cells (Stratagene) and grown to midlog phase in LB media containing carbenicillin $(50 \mu \mathrm{g} / \mathrm{mL})$ at 37 ${ }^{\circ} \mathrm{C}$ with shaking at $220 \mathrm{rpms}$. The cells were cooled to $16^{\circ} \mathrm{C}$ and induced with $0.1 \mathrm{mM}$ IPTG for 
$12 \mathrm{hrs}$. The cells were harvested by centrifugation at $4{ }^{\circ} \mathrm{C}, 5 \mathrm{~K}$ for $30 \mathrm{~min}$. Pellets were then either frozen at $-80{ }^{\circ} \mathrm{C}$ for storage or resuspended in the lysis buffer. The lysis buffer was added at $4{ }^{\circ} \mathrm{C}$ and incubated for $30 \mathrm{~min}(40 \mathrm{~mL}$ of lysis buffer per $1 \mathrm{~L}$ expression. Lysis Buffer: PBS, $100 \mathrm{mM}$ EDTA, $1 \%$ Triton X-100, $10 \%$ glycerol, $1 \mathrm{mg} / \mathrm{mL}$ lysozyme, and protease cocktail III (calbiochem: $100 \mu \mathrm{M}$ AEBSF, $80 \mathrm{nM}$ Aprotinin, $5 \mu \mathrm{M}$ Bestatin, $1.5 \mu \mathrm{M}$ E-64, $2 \mu \mathrm{M}$ Leupeptin, $1 \mu \mathrm{M}$ Pepstatin A) The solution was then sonicated for 4 min followed by addition of DTT (10 $\mathrm{mM}$ ). The soluble fraction was isolated by centrifugation at $35,000 \mathrm{rpms}$ for $30 \mathrm{mins}$ at $4{ }^{\circ} \mathrm{C}$ followed by purification with Glutathione Sepharse 4 Fast Flow (Amersham Biosciences) utilizing their instructions for protein purification. Protein was analyzed by $12 \%$ SDS-Page gel and visualized with coomassie blue dye. Protein was dialyzed with 10K MW cut-off slide-a-lyzer with $3 \mathrm{X} 1.5 \mathrm{~L}$ of $10 \mathrm{mM} \mathrm{MES}, 100 \mathrm{mM} \mathrm{NaCl}$ for at least 2 hours. The protein concentration was determined by a biorad BCA/BSA assay. The purified protein was stored at $4{ }^{\circ} \mathrm{C}$ and luminescence measurements were performed on protein that was no older than 2 weeks.

\section{GST-Crk-LBT}

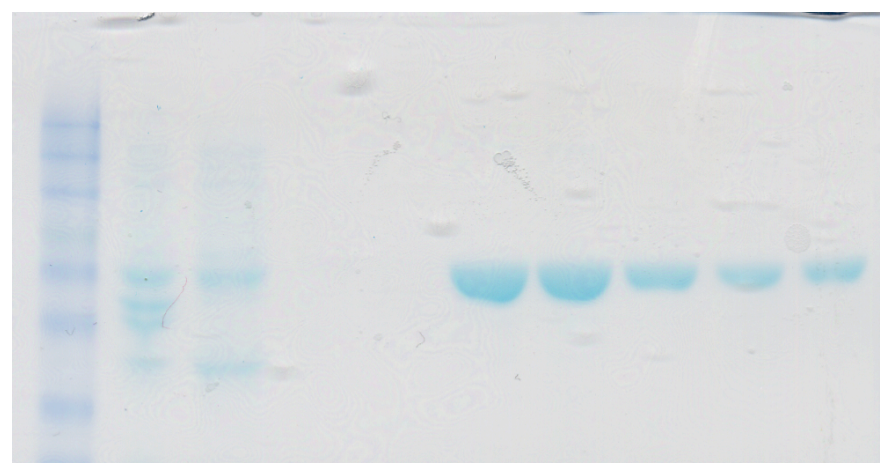
A ladder
B pellet
C flow through
D wash \#1
E wash \#2
F-K elutions

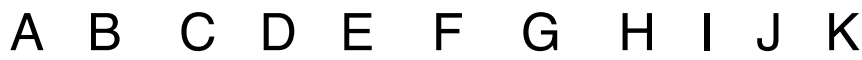

\section{GST-Src-LBT}

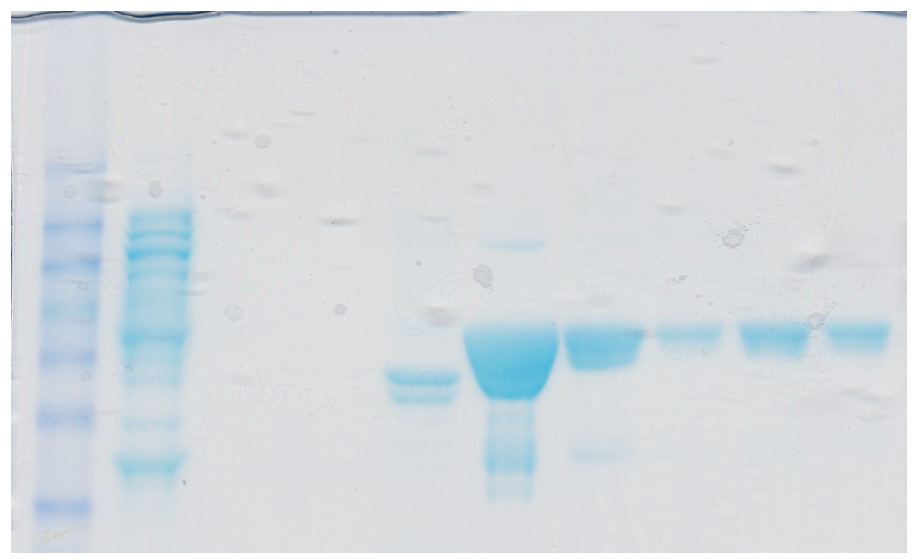
A ladder
B flow through
C wash \#1
D wash \#2
E pellet
F-K elutions

\section{A B C D E F G H I J K}

